\title{
The Effect of Internet Word-of-mouth on Experience Product Sales --- An Empirical Study Based on Film Online Reviews
}

\author{
Feixiang Zhang ${ }^{1}$ \& Yang Yang ${ }^{2,3}$ \\ ${ }^{1}$ College of Communication and Art Design, University of Shanghai for Science and Technology, Shanghai, China \\ ${ }^{2}$ Business School, University of Shanghai for Science and Technology, Shanghai, China \\ ${ }^{3}$ Shanghai Publishing and Printing College, Shanghai, China \\ Correspondence: Feixiang Zhang, College of Communication and Art Design, University of Shanghai for Science \\ and Technology, Shanghai, China.
}

Received: January 29, 2016

Accepted: February 17, 2016

Online Published: March 18, 2016

doi:10.5430/ijba.v7n2p72

URL: http://dx.doi.org/10.5430/ijba.v7n2p72

\begin{abstract}
When purchasing experience products, more and more modern consumers are inclined to make a purchase decision through internet word-of-mouth on third-party websites. Based on a sample panel data of online movie reviews from gewara.com, this paper analyzes the impact of online reviews on movie box-office revenue from three dimensions: review volume, review scores and star reviews. The results show that the online reviews have a significant impact on movie box-office revenue. Specifically, the review volume has a significant positive impact on box-office revenue, and the impact effect shows parabola trends overtime. The impact of star review on box-office revenue mainly occurred in the first week, and the negative effect of 1 star reviews exceeds the positive effect of 5 star reviews. Management implication is proposed based the results.
\end{abstract}

Keywords: internet word-of-mouth, online review, panel data, box-office

\section{Introduction}

Word of mouth (WOM) long has been recognized as a powerful driver of consumer behavior. Consumers tend to make decisions in the light of its word of mouth (WOM) when purchasing products (Keaveney \& Susan M, 1995). In the traditional sense, WOM is the oral communication between people on brands, enterprises, products, services and so on rather than the one for the purpose of the business (Arndt J, 1967). There are studies showing that WOM is the most important factor in purchasing decision making, whose influence is even 7 times greater than news magazines and twice greater than broadcasting advertisement (Katz, Elihu \& Paul F. Lazarsfeld).

With the rapid development of Internet technology, the Internet has not only changed the way of human life and become one of the most important medium of communication, but also brought the new business model and interpersonal communication mode. For the vast number of consumers, it has become one part of consumption to express their opinions on the product in social networking sites, e-commerce sites and other internet platforms. WOM has evolved from the traditional way of one-to-one and the face-to-face oral communication into a way of communicating to many potential consumers in an anonymous environment. IWOM means "any positive or negative statement made by potential, actual, or former customers about a product or company, which is made available to a multitude of people and institutions via the Internet" (Hennig-Thurau et al. 2004). Besides, IWOM information can also be stored, searched and then respread, while the traditional word of mouth is instant and short. Digital media made it possible to see what people were saying and to trace that conversation all the way to a final purchase. IWOM allows consumers to socially interact with one another, exchange product-related information, and make informed purchase decisions via computer-mediated conversations (Blazevic et al. 2013; Hoffman and Novak 1996). Therefore, IWOM has the stronger influence than the traditional WOM by spreading the information endlessly through the Internet channel.

Nelson (1974) classified products in his research into two categories: one for experience products, the other for search products. For the search product, its quality can be confirmed by the search prior to the purchase and usually functional products belong to this category; but for the experience product, its quality can only be concluded after the purchase and usually service products or entertainment products are experience products such as concerts, movies, etc.. Bei (2004) found that compared with consumers who buy search products, consumers buying experience 
products more frequently use the network to obtain product information, and more inclined to accept IWOM.

In recent years, the domestic E-commerce website develops very fast. Gevara website (www.gewara.com), the leading third party website for experience products, which not only allows consumers' comment on movies but also provide online purchase of movie tickets. The paper aims to make an empirical analysis of the relationship between the film online reviews and the movie box office by establishing measurement model on the basis of the panel data collected from the Gevara network, including film reviews, box office, the days of film releases, and the number of screens every day.

\section{Literature and Hypothesis}

On the impact of IWOM on the sales of products, scholars have adopted various measurement models and research methods to measure the communication effect of IWOM from different dimensions. The three most commonly used dimensions are volume, valence and dispersion (Dellarocas C et al., 2007). The theory behind measuring dispersion, or the spread of communication across communities, is that opinions spread quickly within communities, but slowly across them (Granovetter, 1973). The higher the degree of dispersion, the higher the influence of IWOM. Because this study is only confined to one network of Gevara without spreading across communities, the dimension of dispersion can not be employed here. Therefore, this paper mainly analyzes the effect of IWOM on sales from volume and valence.

Volume mainly refers to the number of postings consumers make on a product, which reflects awareness effect of internet word of mouth. Godes \& Mayzlin (2004) believes that the more the number of postings, the more consumers are involved in the discussion of the product, which not only reflects the size of consumers buying the product, but also reflects the intensity of consumer's discussion about the product. The more consumers discuss a product, the higher the chance that other consumers will become aware of it and then more follow-up sales (Godes \& Mayzlin, 2004). A large number of scholars have shown that the number of WOM is positively related to sales. Chen (2004) made an empirical study of the effect of consumer feedback and reviews on sales according to the data collected on the Amazon Web site, which found that more recommendations improved the sales of products on the Amazon site and the number of consumer reviews and sales were positively related. Liu (2006) found that the more the number of comments, the higher the box office through the analysis of the data collected on the Yahoo website. Duan (2008) found the number of consumer reviews had a significantly positive effect on box office revenue in the movie box office research. Thus, we put forward the hypothesis 1:

H1: The number of POSTINGS has a significant positive effect on the movie box office revenue.

Valence means whether consumers'attitude is positive or negative usually by measuring review scores and the ratio of positive or negative statements. It reflects the effect of IWOM. Persuasive effect is that the better the product reviews are, the more likely the potential consumers' attitudes can be changed to buy the product. At present, some scholars have shown that valence of WOM has a significant effect on the sales. In these studies, some showed positive IWOM had a significant effect on the sales while some showed the negative IWOM had a more significant effect than positive one. Clemons (2006) found that the review valence had a positive correlation with beer sales by analyzing consumers' online review on the beer. Hao Yuanyuan (2009) believed that the positive effect of the 5-star rating is greater than the negative effect of the 1-star rating while no significant effect can be found in the effect of medium ratings based on the research data of the box office revenue in the www.boxofficemojo.com and the film online reviews in the Yahoo. It was believed that the unsatisfied consumers will spread the negative WOM to more than 6000 people through the network platform (Hanson, 2000). Through the data research of Amazon and BN website, Chevalier \& Mayzlin (2005) found that the improvement of a book review will increase the book sales and the negative WOM can lower product sales more significant than positive WOM promote product sales. However, there are some opposite research conclusions in some scholars' researches that the word of mouth valence had no significant effect on product sales. Duan (2008) found that the review scores had no significant effect on the box office through the film review score. Chen (2004) found no significant relationship between the consumer review valence and sales through analysis of the data collected from the Amazon website. Liu (2006) found that whether the word of mouth is positive or not had no explanative power by measuring the percentage of positive and negative reviews. Accordingly, the paper hypothesizes that:

H2: IWOM review has a significantly positive effect on box office revenue.

H3: Positive IWOM (5-star review ratio) has a significantly positive effect on the box office revenue.

H4: Negative IWOM (1-star review ratio) has a significantly negative effect on the box office revenue.

H5: Negative IWOM has a more significant effect on the box office revenue than the positive IWOM does.

In addition, other related important factors need to be included in the study of the effect of IWOM on the movie box 
office revenue, such as the number of film screenings, the weekend effect and running days and so on. Swami's (1999) research believed that there was a significantly positive correlation between the number of film screenings and the box office revenue. Duan (2008) found that the weekend box office will usually come with the peak of cycle and the running days in movie theaters had a negative correlation with the box office. Thus, the following hypotheses are put forward in this paper:

H6: Number of film screenings has a significantly positive effect on the box office revenue.

H7: Weekends have a significantly positive effect on the box office revenue of release weekends.

H8: Running days has a significantly negative effect on the box office revenue of the release day.

In the research of the relationship between IWOM and product sales, endogenity is also an important factor. The box office revenue is usually related with the quality of the film, the star popularity, and the directors' star power or other factors, which may also be related to IWOM and box office revenue, and then endogenity is caused.

\section{Data Description and Data Collection}

The study chose Gewara internet (www.gewara.com) as the film data source mainly because it is the leading third party website of experience products at home, which provides movie tickets online purchasing service and only allows film consumers to make film reviews and ratings to ensure the authenticity and objectivity of film reviews. The Gewara with membership of more than 150 million now accounts for $75 \%$ of national market share in the online movie seat selection, and can be seen as a good representative in the third party websites of experience products. In addition, the research data in the literature (Hao Yuanyuan et al., 2009) mainly was from the website of movies.yahoo.com, which is independent movie online review sites rather than purchasing site for experience products. Therefore, choosing Gewara as the movie data source made it possible to compare with the research results made by Hao (2009).

Film data in November \& December in 2013 on the Gewara website were collected through programming, including the number of ticket purchasers, review volume, review scores, ratio of star reviews, running days, the number of film screenings one day and so on. Because Gewara website takes numbers of ticket purchasers as statistical data of box office rather than the direct box office revenue, the study adopted the number of ticket purchasers as box office revenue. To ensure the validity of analysis results, 21 films were chosen as the sample by eliminating some films whose information were seriously missing. Considering the film life cycle for 6 weeks (Elberse, A.; J. Eliashberg, 2003), online purchasing service cycle for 4 weeks, and the easiness to compare with the results of the literature (Hao Yuanyuan et al., 2009), this paper selected the time series of 28 days as the time observation point and then got the panel data of the capacity of 588 (the 21 section members x 28 observation points). Table 1 showed the result of descriptive statistics of the data. The IWOM data contained review volume, review scores and the ratio of each star for each movie. The mean value of the review volume is 2604 , quite far from the median of 1138, which showed some films won a lot of consumer reviews and among them one movie got comments as many as 15208 . Second, the mean value of the movie review scores (Total Score 10) is 7.38, close to the median of 7.3. The highest score is 9 and the lowest is 5.5. In terms of the percentage of the film each star reviews, 5-star reviews, 4-star reviews, 3-star reviews accounted for most part of reviews, respectively $36.15 \%, 21.21 \%$ and $25.91 \%$ while 2 -star reviews and 1 -star reviews were $7.02 \%$ and $9.5 \%$ respectively.

Table 1. Descriptive statistics of sample films

\begin{tabular}{cccccc}
\hline variables & Mean value & $\begin{array}{c}\text { Standard } \\
\text { deviation }\end{array}$ & median & $\begin{array}{c}\text { Minimum } \\
\text { value }\end{array}$ & $\begin{array}{c}\text { Maximum } \\
\text { value }\end{array}$ \\
\hline Ticket buyer & 84265.47 & 5671.36 & 28058 & 231 & 1745187 \\
\hline Review number & 2604.32 & 145.86 & 1138 & 11 & 15208 \\
\hline Review score & 7.38 & 0.76 & 7.3 & 5.5 & $73 \%$ \\
\hline 5 stars & $36.15 \%$ & $14.63 \%$ & $34 \%$ & $15 \%$ & $38 \%$ \\
\hline 4 stars & $21.21 \%$ & $10.45 \%$ & $22 \%$ & 0 & $44 \%$ \\
\hline 3 stars & $25.91 \%$ & $8.86 \%$ & $26 \%$ & $9 \%$ & $20 \%$ \\
\hline 2 stars & $7.02 \%$ & $5.09 \%$ & $6 \%$ & 0 & $41 \%$ \\
\hline 1 star & $9.5 \%$ & $10.04 \%$ & $8 \%$ & 0 & 3136 \\
\hline Film shows & 297.96 & 578.84 & 11 & 0 & 0 \\
\hline
\end{tabular}

Note: sample number $\mathrm{N}=588$ 


\section{Model Establishment}

Based on the above literature review and hypothesis, a panel data regression model was established, and the fixed effect $\mu_{i}$ was introduced into the model to control all the effect of factors not involved in the model, such as film quality, directors' and actors' star power of box office. Both dependent variable of the number of ticket purchasers and independent variables including the number of film screenings, release time, review volume and ratings took natural logarithmic form, whose advantage is the potential nonlinear relationship can be transformed into a linear relationship, and makes the result of the regression model more robust (Gong shiyang et al., 2013). Regression models are as follows:

$$
\begin{aligned}
& \text { Ln Revenue }_{i t}=C+\alpha_{1} \text { LnVol }_{i t}+\alpha_{2} \text { LnVal }_{i t}+\alpha_{3} \text { Star }_{i t}+\alpha_{4} \text { Star }_{i t}+\alpha_{5} \text { LnTime }_{t} \\
& +\alpha_{6} \text { LnCinema }_{i t}+\alpha_{7} \text { Weekend }_{i t}+\mu_{i}+\varepsilon_{i t}
\end{aligned}
$$

In the model, $i=1, \cdots n$ is for the number of film samples, $t=1, \cdots n$ for time, Ln Revenue for the natural logarithm of the number of film ticket purchasers on Gewara website on the th film release day, LnVol means the natural logarithm of review volume on the $t$ th film release day, LnVal for the natural logarithm of review scores on the th film release day, LnTime for the natural logarithm of the number of running days, LnCinema for the natural logarithm of the number of film screenings on the $t$ th film release day, star 1 and star 5 for the ratio of 1-star ratings and the ratio of 5-star ratings on the th film release day, Weekend for the dummy variable of weekends on the $t$ th film release day ( 1 means weekends, 0 means work days). $\mu_{i}$ is a fixed effect, used to control the impact of the non-observational effects, such as the quality of the film, the popularity of the stars, the director's star power of box office appeal, etc..

\section{Model Analysis}

EVIEWS6.0 was used to analyze the constructed panel data regression model by collecting $21 \times 28$ panel data of sample films. In the process of modeling, due to possible multicollinearity of independent variables, the effects of individual variable were examined before the stepwise regression analysis was made based on the significant effect of individual variables. Because the assumed non-observed effect $\mu_{i}$ is related to many IWOM variables in the model, fixed effects model was used to replace the random effects model to make a regression analysis of panel data (Gong shiyang et al., 2013). In addition, from the results of Hausman test, the fixed effects model was better than the random effect model. The results of regression model are shown in Table 2.

Table 2. Model parameters' influence on box office

\begin{tabular}{cccccc}
\hline Independent variables & Model 1 & Model 2 & Model 3 & Model 4 & Model 5 \\
\hline \multirow{2}{*}{$\mathrm{C}$} & $0.8818^{* *}$ & $1.7454^{* * *}$ & 2.6599 & 5.9521 & 5.7806 \\
& $(0.4464)$ & $(0.5639)$ & $(4.7569)$ & $(5.1430)$ & $(5.1868)$ \\
\hline \multirow{2}{*}{ LnTime } & $-0.2415^{* *}$ & $-0.1351^{*}$ & $-0.1413^{* *}$ & $-0.0755^{*}$ & $-0.0570^{*}$ \\
& $(0.1044)$ & $(0.1208)$ & $(0.1251)$ & $(0.1310)$ & $(0.1470)$ \\
\hline \multirow{2}{*}{ LnCinema } & $0.9903^{* * *}$ & $0.7380^{* * *}$ & $0.7366^{* * *}$ & $0.7514^{* * *}$ & $0.7586^{* * *}$ \\
& $(0.0656)$ & $(0.0758)$ & $(0.0763)$ & $(0.0767)$ & $(0.0809)$ \\
\hline \multirow{2}{*}{ Weekend } & $0.3520^{* * *}$ & $0.4382^{* * *}$ & $0.4395^{* * *}$ & $0.4416^{* * *}$ & $0.4379^{* * * *}$ \\
& $(0.1055)$ & $(0.1165)$ & $(0.1168)$ & $(0.1165)$ & $(0.1174)$ \\
\hline \multirow{2}{*}{ LnVol } & & $0.2476^{* * *}$ & $0.2466^{* * *}$ & $0.2705^{* * *}$ & $0.2708^{* * *}$ \\
& & $(0.0798)$ & $(0.0801)$ & $(0.0812)$ & $(0.0813)$ \\
\hline \multirow{2}{*}{ LnVal } & & -0.4418 & -2.1242 & -2.0749 \\
& & & $(2.2819)$ & $(2.4918)$ & $(2.5017)$ \\
\hline \multirow{2}{*}{ star1 } & & & $-0.2033^{*}$ & $-0.2082^{*}$ \\
& & & & $(0.1227)$ & $(0.1240)$ \\
\hline
\end{tabular}




\begin{tabular}{cccccc}
\hline star5 & & & & 0.1708 \\
$(0.6109)$ \\
\hline R-squared & 0.9048 & 0.9125 & 0.9125 & 0.9132 & 0.9132 \\
\hline Adjusted R-squared & 0.9009 & 0.9059 & 0.9056 & 0.9060 & 0.9058 \\
\hline F-statistic & 232.6934 & 138.5289 & 132.5880 & 128.2943 & 123.1863 \\
\hline Sum squared resid & 747.4984 & 263.2723 & 263.2413 & 260.98 & 260.9155 \\
\hline
\end{tabular}

Note: the value in bracket is standard error, *means $\mathrm{p}<0.05 ; * *$ means $\mathrm{p}<0.01 ; * * *$ means $\mathrm{p}<0.001$

From Table 2, IWOM related variables are not in Model 1, in which only regression analysis of the number of ticket purchasers and control variables was made, and the regression results showed all control variables had significant effects on dependent variables. LnTime coefficient was significantly negative $\left(\alpha_{5}=-0.2415, p<0.01\right)$, which showed running days had significantly negative effect on the box office revenue on the release day. That is, the longer the running time, the lower box office revenue on the very release day. Then hypothesis H8 is supported. LnCinema coefficient was significantly positive $\left(\alpha_{6}=-0.2415, \mathrm{p}<0.001\right)$, which meant the number of film screenings had significantly positive effect on the box office revenue on the release day, that is, the more film screenings on the film release day, the more the box office revenue. Then hypothesis H6 is supported. The coefficient of Weekend was significantly positive $(7=0.3520, \mathrm{p}<0.001)$, which means that weekends had significantly positive effect on the box office revenue. That is, the box office revenue during weekends could be higher than that in the work days. Then, hypothesis $\mathrm{H} 7$ is supported.

In the models $2,3,4,5$, the four IWOM related variables were added one by one, including review volume, review scores, 1-star ratings and 5-star ratings. After adding these 4 variables to the models, $\mathrm{R}^{2}$ gradually increased from 0.9048 to 0.9132 , which indicated adding these variables to the models made models have more explanatory. The variable LnVol representing movie review volume was added to the Model 2 on the basis of the model 1. Regression results showed that LnVol coefficient is significantly positive (alpha $1=0.2476, \mathrm{P}<0.001$ ), which meant the more film reviews made by consumers on Gewara website, the more film purchasers and the more box office revenue. Then, hypothesis H1is supported. This conclusion is consistent with the research results of the most literature. LnVol coefficient can also be interpreted as $0.25 \%$ increase in the number of film ticket purchasers for each $1 \%$ increase in review volume. After adding the variable LnVal of review scores in the model 3, the regression results showed LnVal had insignificant effect on the number of film tickets purchasers, that is, film review scores had no significant effect on box office revenue, which verified the Duan (2008) and Chen's (2004) research conclusions. Then hypothesis H2 is not supported. After adding the variable star1 of 1-star rating in the model 4, the regression results showed star1 coefficient had significantly negative effect on box office revenue $\left(\alpha_{3}=-0.2033, p<0.05\right)$, which meant the more 1-star ratings about one film on the Gewara website would result in the less film ticket purchasers and the poorer box office revenue. Then hypothesis H4 is supported. In the model 5, the variable star 5 of 5 -star ratings was added and the regression results showed that the variable of star5 had no significant effect on the box office revenue. H3 assumption is not supported. Because the hypothesis $\mathrm{H} 4$ is supported but the hypothesis $\mathrm{H} 3$ is not, the hypothesis $\mathrm{H} 5$ is supported. That is, the effect of negative IWOM on the box office revenue is greater than that of the positive IWOM on the box office revenue. Although this is contrary to the conclusions of the literature (Hao yuanyuan et al., 2009), but it is consistent with the literature (Hanson W A, 2000) and (Chevalier, J. \& D. Mayzlin, 2005).

As the sample took 28 days of film release as observation point, the regression analysis of the effect of IWOM on box office revenue each week during 4 weeks after film release was made so as to analyze the effect of IWOM in the different stages of cycle on the film box office revenue. Regression analysis results were shown in Table 3.

Table 3. Effect of model parameters on box office

\begin{tabular}{ccccc}
\hline Independent variables & First week & Second week & Third week & Fourth week \\
\hline \multirow{2}{*}{$\mathrm{C}$} & $0.8818^{* *}$ & $-6.0358^{* *}$ & -21.4030 & -1.0072 \\
& $(0.4464)$ & $(4.1078)$ & $(14.3804)$ & $(4.2044)$ \\
\hline \multirow{2}{*}{ LnTime } & $-0.7042^{* * *}$ & $-0.4486^{*}$ & $-0.4465^{*}$ & -0.0083 \\
& $(0.1881)$ & $(0.1575)$ & $(0.2187)$ & $(1.2408)$ \\
\hline \multirow{2}{*}{ LnCinema } & $0.5947^{* *}$ & $1.6121^{* * *}$ & $0.0530^{* *}$ & -8.4087 \\
& $(0.2052)$ & $(0.1171)$ & $(0.2275)$ & $(4.4995)$ \\
\hline \multirow{2}{*}{ Weekend } & $0.6476^{* * *}$ & $0.2885^{* * *}$ & $0.1854^{* *}$ & 0.1554 \\
& $(0.1946)$ & $(0.0611)$ & $(0.0553)$ & $(0.2007)$ \\
\hline LnVol & $0.2996^{* * *}$ & $3.2414^{* * *}$ & $5.2282^{* * *}$ & $1.3089^{* * *}$
\end{tabular}




\begin{tabular}{ccccc}
\hline & $(0.0870)$ & $(0.0910)$ & $(0.3243)$ & $(0.1253)$ \\
\hline \multirow{2}{*}{ LnVal } & -2.1907 & -0.0465 & -1.5407 & -19.7901 \\
& $(3.4319)$ & $(0.1158)$ & $(0.1812)$ & $(34.7189)$ \\
\multirow{2}{*}{ star1 } & $-0.3308^{*}$ & 10.9693 & 11.8170 & 34.4116 \\
& $(0.1499)$ & $(6.7419)$ & $(13.0947)$ & $(55.0808)$ \\
\hline \multirow{2}{*}{ star5 } & $0.1178^{*}$ & 0.4280 & 0.2057 & 46.9843 \\
& $(0.0475)$ & $(0.1498)$ & $(0.2728)$ & $(54.3584)$ \\
\hline R-squared & 0.9271 & 0.9944 & 0.9970 & 0.9421 \\
\hline Adjusted R-squared & 0.9106 & 0.9931 & 0.9961 & 0.9290 \\
\hline F-statistic & 56.0836 & 783.2687 & 1119.133 & 71.7599 \\
\hline Sum squared resid & 125.0758 & 11.9722 & 2.6685 & 75.8316 \\
\hline
\end{tabular}

Note: the value in bracket is standard error, ${ }^{*}$ means $\mathrm{p}<0.05 ; * *$ means $\mathrm{p}<0.01 ; * * *$ means $\mathrm{p}<0.001$

From Table 3, it was shown that the number of POSTINGS had the significantly positive effects on movie box office revenue from the first week of the film release to the fourth week. The effects were 0.2996 the first week, 3.2414 second week, increased to 5.2282 third week, and then decreased to 1.3089 from the fourth week. Then the hypothesis $\mathrm{H} 1$ is supported. The effect of the number of postings on box office revenue gradually increased in the first few weeks, and finally gradually decreased. This research conclusion is consistent with the result of the literature (Hao yuanyuan et al., 2009). The online review scores had no significant effect on the film box office revenues from the first week to the fourth week. Then hypothesis $\mathrm{H} 2$ still is not supported. For star ratings, the model 4 and the model 5 in the table 2 showed 1-star ratings had the significantly negative effect on the box office revenue for the entire 28 days; 5 -star ratings has no significant effect on the box office revenue for the entire 28 days. However, the regression results in the Table 3 showed that 1 -star ratings had the significantly negative effect on box office revenue only within the first week $\left(\alpha_{3}=-0.3308, \mathrm{p}<0.05\right)$ but no significant effect from the beginning of the second week.

On the whole, 5-star ratings had not a significant effect on the box office revenue, but had a significant effect on the box office revenue in the first week of film release $\left(\alpha_{4}=0.1178, \mathrm{p}<0.05\right)$. In terms of star 1 and star5 coefficient, the effect of 1-star ratings on box office revenue $(-0.3308)$ was greater than that of 5 -star ratings on box office revenue $(0.1178)$ in the first week of film release. That is, $1 \%$ increase in 1-star ratings can bring decrease in the box office revenue by $0.3308 \%$ while $1 \%$ increase in 5 -star ratings can cause increase in box office revenue by $0.1178 \%$. Therefore, hypotheses H3, H4, H5 are supported in the first week of film release.

\section{Conclusions and Discussions}

This paper used the panel data of film online reviews on the Gevara website, which is the leading third party website for experience products, to empirically analyze the relationship between online reviews and the box office revenue. There are two main findings in the study:

(1) The number of postings has the significantly positive effect on the box office revenue from the first week to the fourth week of the movie release and the impact of the effect with time showing a parabola shape. It not only verified the awareness effect proposed in the literature, which means the higher intensity of consumers' discussion about one product will lead to the more chance of the product's being known by consumers and then bring more follow-up sales, but also proved the awareness effect of IWOM with time. The possible explanation for this tendency is that with the longer running time of the film consumers, there will be more and more channels for consumers to get film information, including traditional WOM, media promotion and advertisement. These channels play the role of substituting IWOM and lessen the communication effect of IWOM.

(2) Star ratings reflect consumers' personal judgment on the film, that is, the persuasive effect. The effect of star ratings on box office revenue does not run through the entire life cycle of the movie release, but mainly happens in the first week. It is the first week effect. That is, in the first week of the movie release, potential consumers will make a purchasing decision based on the star ratings of the movie, but the persuasive effect gradually diminishes from the second week, and no change of potential consumers' attitudes can be brought. And in the star ratings, despite the 5 -star ratings of $36.15 \%$ and 1 -star ratings of only $9.5 \%$, the effect of 1 -star negative ratings on the box office revenue is greater than that of 5-star positive ratings. That is, the negative IWOM has the greater effect on box office revenue than the positive IWOM.

\section{Implications}

According to the research conclusions, some managerial implications could be got. 
(1) Due to the effect of IWOM on the movie box office revenue mainly coming from the awareness effect, the film network sellers should actively build and improve the consumer online review system on the third party websites, encourage consumers to actively participate in online reviews, enhance the intensity of product discussion made by consumers with the fully displaying the IWOM awareness effect to promote rapid growth of movie box office revenue.

(2) According to the research findings, potential consumers are more sensitive to negative IWOM within the first week of the movie release. Therefore, the film network sellers should realize how to avoid the dispersion of negative IWOM on the internet is preferred to the promotion of positive IWOM on the internet. Thus, the movie network sellers should focus on and track the internet word of mouth during the first week in order to effectively curb the spread of negative word of mouth on the network.

\section{References}

Arndt, J. (1967). Role of Product-related Conversations in the Diffusion of a New Product. Journal of Marketing Research, (4), 291-295. http://dx.doi.org/10.2307/3149462

Bei, L., \& Chen, E. Y. (2004). Widdows R. Consumers' online Information search Behavior and the Phenomenon of Search Experience Products. Journal of Family and Economic, 25(4), 449-467.

Chen, P-Y., Wu, S-Y., \& Yoon, J. (2004). The Impact of Online Recommendations and Consumer Feedback on Sales. Proceeding of International Conference on Information Systems (ICIS), Washington, D.C., 711-724.

Chevalier, J., \& Mayzlin, D. (2005). The Effect of Word of Mouth on Sales: Online Book Reviews. Journal of Marketing Research, 345-354.

Clemons, E. K., Gao, G., \& Hitt, L. M. (2006). When Online Reviews Meet Hyper Differentiation: A Study of the Craft Beer Industry. Journal of Management Information Systems, 23(2), 149-171. http://dx.doi.org/10.2753/MIS0742-1222230207

Dellarocas, C., Zhang, X., \& Awad, N. F. (2007). Exploring the Value of Online Product Reviews in Forecasting Sales: The Case of Motion Pictures. Journal of Interactive Marketing, 21(4), 23-45. http://dx.doi.org/10.1002/dir.20087

Duan, W., Gu, B., \& Whinston, A. B. (2008). Do online reviews matter? An empirical investigation of panel data. Decision SupportSystems, 45(4), 1007-1016. http://dx.doi.org/10.1016/j.dss.2008.04.001

Elberse, A., \& Eliashberg, J. (2003). Demand and Supply Dynamics for Sequentially Released Products in International Markets: The Case of Motion Pictures. Marketing Science, 22, 329-354. http://dx.doi.org/10.1287/mksc.22.3.329.17740

Godes, D., \& Mayzlin, D. (2004). Using Online Conversations to Study Word-of-mouth Communication. Marketing Science, 23(4), 545-560. http://dx.doi.org/10.1287/mksc.1040.0071

Gong, S., Liu, X., \& Zhao, P. (2013). How do online consumes' reviews affect product sales?-An Empirical research based on online book reviews. China Soft Science, (6), 171-183.

Hanson, W. A. (2000). Principles of Internet Marketing. Ohio: South Western College Publishing, 4.

Hao, Y., Li, Z., Yi, J, \& Ye, Q. (2009). An Empirical Study of the Effect of Online Review Emotional Preference on Sales based on Panel Data. Management Review, (10), 95-103.

Henning, T. T., Gwinner, K. P., \& Walsh, G., et al. (2004). Electronic Word of mouth Via Consumer opinion Platforms: What Motivates Consumers to Articulate Themselves on the Internet. Journal of Interactive Marketing, 18(1), 38-52. http://dx.doi.org/10.1002/dir.10073

Katz, E., \& Paul, F. L. (1955). Personal Influence: The Part Played by People in the Flow of Mass Communications. Free Press, (12), 113-115.

Keaveney, S. M. (1995). Customer Switching Behaviour in Service Industries: An Exploratory Study. Journal of Marketing, 59(2), 71-82. http://dx.doi.org/10.2307/1252074

Liu, Y. (2006). Word of Mouth for Movies: Its Dynamics and Impact on Box Office revenue. Journal of Marketing, 70(3), 74-89. http://dx.doi.org/10.1509/jmkg.70.3.74

Nelson, P. (1974). Advertising as Information. Journal of Political Economy, 81, 729-754. http://dx.doi.org/10.1086/260231

Swami, S., Eliashberg, J., \& Weinberg, C. B. (1999). Silver Screener: A Modeling Approach to Movie Screens Management. Marketing Science, 18, 352-372. http://dx.doi.org/10.1287/mksc.18.3.352 